\title{
LOS LIMITES DEL CIRCULO EN LUCIO MANSILLA
}

Vamos a intentar senalar en "Mi primer robo" de Lucio Mansilla algunos aspectos que son una constante en las "Causeries" y que, a nuestro juicio, pueden vincularse con ciertos rasgos de otros escritores del 80 y su visión del mundo.

Tomamos "Mi primer robo". que es uno de los artículos más cortos de Entre Nos, aparentemente más "inocente", es decir, en una primera lectura podría parecer que lo que importa es sólo la anécdota, pero no tardamos en ver en él aquellas constantes que vamos a señalar, si bien menos evidentes, menos explicitadas.

Comenzando por el principio, encontramos (antes del título) la dedicatoria que nos va a señalar, con precisión exacta, un lector, aquel a quien el artículo se dedica.

Todos los artículos de Entre Nos comienzan con una dedicatoria. Los destinatarios son diferentes, varían, pero hay un elemento común: son los miembros de un grupo, aquellos que rodean a Roca, el Presidente de la República, los que son miembros de un mismo Club.

Este círculo cerrado del club, es el círculo cerrado de sus lectores, no el público anónimo, sino con nombre y apellido: Carlos Pellegrini, Florencio Madero, Benjamín Posse, Mariano de Vedia... Podemos seguir, pero de ninguna manera hasta el infinito...

Apuntamos aquí un primer rasgo respecto de lo que inferimos como una concepción del escritor y del lector.

Mansilla no escribe para un mercado anónimo, no es un profesional (por lo menos aparenta no serlo).

Esto se va a reforzar con la elección del tema (aspecto que trataremos más adelante): Algo intrascendente, que busca divertir, algo cuya escritura (que por otra parte aparenta no ser tal, pues el carácter oral va a ser constantemente remarcado) no constituye un trabajo.

El círculo de lectores de Mansilla, aquellos a los que él 
reconoce como tales, los que tan llama lectores empíricos, «o incide con su lector modelo, al que êl se dirige, cerrando el círculo de manera explícita, por medio de lo que Viñas llama "guiños". Son claves, códigos culturales, alusiones, menciones, que sólo los iniciados, es decir, los miembros del círculo, que adquiere aquí características físicas: los que se encuentran, fre cuentan esos lugares, pueden conocer Lo que dijo alguien el otro día en casa de alguien.

"Me pidió Ud. que le refiriera el cuento que le había contado en casa de nuestro noble amigo el $\mathrm{Sr}$. Presidente de la República, doctor Don Miguel Juárez Celman". p. 46

"Dr. Pellegrini, me preguntó ud. en el Politeama, estando en el palco del señor Presidente de la República..." p. 82

Esta búsqueda de complicidad, establecida por este tipo de referencias es en realidad la puesta de manifiesto de una complicidad existente, previa a la literatura, y que continuará después de terminado el artículo.

Podemos relacionar esto con la continuidad de los artículos, que son también un círculo: "Pero, decididamente, concluirá el jueves y seguirá con "Los siete platos de arroz con leche", cuento que le tengo ofrecido a Benjamín Posse". p. 77

Complicidad que se hace extensiva al título: "Mi primer robo". Es evidente que el lector no tendrá en ningún momento dudas sobre el hecho de que ese robo será algo original, alguna "salida" divertida de Mansilla, al que todos conocen, nadie dudará de que no se trata de un robo verdadero, no hay inquietud del lector ante esto, pero sí se despierta la curiosidad sobre su ingenio, sobre la anécdota que se prevé, sin duda, divertida. Esto se repite en "De cómo el hambre me hizo escritor", donde la situación se hace más explícita: "Salí de la cárcel... así como suena, de la cárcel, no han oído Uds. mal". p. 102.

Todos saben dónde están y quiénes son, tienen un contacto continuo, se encuentran, conversan. Estas conversaciones son continuación de otras. Son iguales.

Podemos señalar aquí un "En la sangre" de Mansilla, que sería opuesta (una sangre opuesta) a la del "tachero" de Cambaceres, por ejemplo. Aquel tenía la maldad En la sangre, que transmite a su hijo. Este, Mansilla, tiene la "bondad" en la sangre, que le ha sido transmitida por su familia.

Aquí marcamos otro punto importante: la prosapia, las genealogías. Aquellos conocidos por todos: Los dueños de las casas patriarcales, los que tenían propiedades desde antiguo, los que tenían sirvientes que venían de antiguos esclavos.

El círculo se amplía al pasado, pero se mantiene cerrado: La mención de su tía (en "Mi primer robo") es breve, no 
está dı "tada, perı tampocu es necesario. No hace talta más que su nombre. María Rozas, los lectores no precisan más.

Fs posible señalar en este punto una doble oposición res. pecto de "lan siete platos de arroz con leche". causerie a la que trataremos de limitar nuestras comparaciones, y en la que todos los elementos señalados se repiten, aunque casi siempre más explicıtados.

Encontramos en estos dos artículos elementos que, si bien se repiten, como dijimos, se tratan de manera diferente. En el (aso que vamos a senalar su tratamiento es opuesto.

I) L.a lamilia. En "Mi primer robo", dijimos, sólo menriona a su tía, sin extenderse sobre sus vínculos familiares, por todos conocidos.

2) La situación económica de la tamilia. En "Mi prımer..." la "pobreza" de su tío es detallada minuciosamente.

En "Los siete platos..." encontramos el juego inverso:

1) El tío, sobre el cual se dan detalles respecto de su ubicación en la realidad, la relación con su gente, la situación de su gobierno. (Como veremos más adelante, aquello que se dice de su tío constituye uno de los que Ilamamos aparentes intersticios del relatol

2) La riqueza de su padre. (Cuando el barco tiene que partir, sin que él haya sido recibido por su tío para despedirse, el padre se ve obligado a pagarle estadías). Esta riqueza inmensa no es explicitada, sólo se alude a ella al pasar, evitando el "mal gusto" de detallarla.

Nos remite ésto a otro aspecto: La vuelta del círculo hacia atrás, hacia atrás en el tiempo, para volver a un pasado al que se refiere también el tema, los temas de las causeries, que muestran el pasado como algo agradable.

Y aquí una contradicción, pero que en realidad es solo aparente, y puede señalarse tanto en este artículo como en "Los siete platos..." y en las otras causeries: El liberal Mansilla, que apoya a Roca, ve el pasado como algo idílico, aquel pasado saladerista, patriarcal, de la Gran Aldea, anterior a la transformación de Buenos Aires, que es apoyada racionalmente, pero de la que, en el texto, aparece una crítica. "Tenía, sin embargo, casa propia en la ciudad, grande y cómoda, amueblada con lo necesario para que fuera confortable, no como ahora que las casas más pobres parecen juguetería y las más ricas, bazares... (p. 593) 
Ese pasado, en Mansilla, no es cualquier pasado, sıno el de un testigo privilegiado "... y tendréis la vera efigie del hombre que más poder ha tenido en América y cuyo estudio psicológico in extenso sólo podré hacer yo, porque soy sбlo yo el único que ha buscado en antecedentes, que otros no puede conseguir, la explicación de una naturaleza tan extraordinaria como ésta". P. 94. ("Los siete platos de arroz con leche").

Aquel que conoce la Historia "desde adentro", la historia que queda aprisionada dentro del círculo, es uno de los mis mos, de los que ahora también hacen la historia, sus amigos.

Al referirnos a la alusión a Rosas, en "Los siete platos de arroz con leche", hablábamos de una contradicción aparente, $y$ es que en este momento, los tajantes límites rosista antirosista de treinta años atrás se han esfumado, y los antiguos enemigos constituyen un grupo que se homogeiniza frente al nuevo y verdadero peligro, aquellos inmigrantes que van a cambiar el panorama socio-político de la Argentina, contra los que advierte Cambaceres en En la sangre. trascendente.

Estilo "coloquial", historia "coloquial", aparentemente in-

Este aspecto se vincula también con el del personaje. El protagonista es él, Lucio, niño, adolescente, hombre joven. Sus actos no interesan, forman parte de la anécdota intrascendente, son intrascendentes, el comerse tantos platos de arroz con leche, robar dulce, escribir artículos por "hambre", hambre bre que tambien merece escribirse entre comillas.

Lo que importa es la persona: Lucio, a quien todos conocen, que conoce a Rosas, al Gobernador de Sta. Fe, a Roca, a Vélez Sársfield, etc.. La persona que se mueve con comodidad dentro del círculo.

Lo que señalamos aquí se extiende a todos sus personajes. "¿Y quiénes eran ellos? Antes de proseguir, aunque todo el mundo pueda llamarse Santiago y Miguel.

Santiago era el padre de Santiaguito Arcos, el eximio pintor, que todos los argentinos de algún fuste que van a París no dejan de conocer.

Y Miguel, ¿Quién era? ...¿iMiguel? Este Miguel a secas, era nada menos que Miguel de los Santos Alvarez, el íntimo amigo de Espronceda"... (P. 39-40).

En todos los personajes de las causeries, lo que importa es eso: la persona, quiénes son.

Llegamos aquí a un punto que nos parece central. Se comienzan a delinear rasgos que consideramos importantes.

a) Los personajes importan, no por lo que hacen, sino 
por quiénes son.

b) Justamente, lo que hacen, la anécotota, es intrascendente.

Dijimos que lo intrascendente era evidente. Demasiado evidente, podemos agrigar.

Al avanzar en la lectura vemos que en el relato de la anécdota, aparente tema central, abundan las digresiones que la van "cortando".

Pensamos que estas disgresiones son lo realmente importante del relato, aparentes intersticios de lo narrado, pero el verdadero tema principal.

Alí es donde lo que interesa es contado: la familia, la historia, la prosapia, el círculo de amigos, la riqueza, son puestos de manifiesto. Aquí se hacen los guiños al lector. "Ya lo veis, os hago confidenclas, cuando es una historia lo que os debo". p. 140.

Es decir que el hecho de que la aparente trama principal esté constantemente cortada por digresiones no es casual. Se la corta para introducir en ella lo que sí es central en la causerie.

Ese estilo, "descuidado", "improvisado", oral, no es realmente tan descuidado ni tan espontáneo. Esas digresiones, como dijimos, son la parte más importante del relato. Es necesario cortar la anécdota para introducirlas, y lo intrascendente de la anécdota permite estas interrupciones.

Ese aparente descuido, esa improvisación propia de lo oral se convierte entonces en una exigencia del relato, así como el tema, su intrascendencia.

$O$ sea que aquel "pero volvamos el tema", tan repetido por Mansilla, es en realidad, salgamos del tema, y volvamos a la anécdota, que nos dará pie para otra digresiôn... donde está lo fundamental del relato.

Podemos también vincular este estilo coloquial, oral, que consideramos una exigencia del relato, con una concepción de la función de la literatura y del escritor que ya mencionamos: entretener, divertir, algo que se improvisa, sobre lo que no se establece un trabajo, no es una profesión. El escritor no es, para Mansilla, de ninguna manera un profesional.

Si bien lo espontáneo puede relacionarse con el romanticismo, hay algo fundamentalmente diferente. No se puede siquiera mencionar la palabra inspiración (ésta es algo demasiado serio, grandilocuente), hay en cambio, ingenio.

Estilo oral, coloquial, "entre nos", al que sólo le falta el gesto, la voz (esa que tenemos en las charlas del club), y Mansilla se lamenta de esta carencia de la lengua escrita, así 
como se enorgullece de ser capaz de escribir como habla. "¿Qué es lo que hace usted, general, para escribir como habla" p. 109 .

Podemos remarcar, como rasgo de modernidad, la utilı zación del lenguaje oral como base del relato.

Sin embargo, hay un uso frecuente de la bastardilla: Se utiliza para códigos culturales precisos: idiomas que el lector sin duda entiende, el francés, italiano, inglés.

Pero la bastardilla no es utilizada sólo para remarcar estas frases que exigirían cierto nivel cultural al lector, sino que se hace de ella un doble uso, pues se utiliza también para palabras vulgares, tal vez consideradas demasiado coloquiales.

Es decir que la bastardilla señalaría todo aquello que escapa de la lengua oral común. Respecto de esto es ilustrativo el hecho de que no siempre para las palabras que llamamos vulgares Mansita usa la bastardilla, o sea que se trataría de palabras que son vulgares, sí, pero de uso tan común y corriente que se han incorporado a este lenguaje "oral" como pertenecientes a él, sin que se considere necesario subrayarlas.

Por supuesto que los límites aquí son imprecisos y contradictorios. Bâstenos señalar unos pocos ejemplos:

En bastardilla

tata

monumentales

Sin bastardilla

iChe!

Espichar

Otro recurso del estilo, muy utilizado, es la ironía. Esta ironía que, a nuestro juicio busca des-sacralizar el relato, tiene también una función de complicidad, pero "desde adentro", dirigida a los nuestros.

Por ejemplo, en "Mi primer robo", son objeto de ironía su padre y su madre. La crítica, y en aspectos inocentes, le está permitida a él, pero recordemos que se batió dieciséis veces a duelo con aquellos que, según él, habían ofendido sus imágenes.

De la misma manera aparecen la pelada de Roca ( $p$. 103): "Mi insolvencia de dinero era mayor que la insolvencia capilar de Roca o la mía propia...", el robo de Mansilla, su encarcelamiento.

Es decir que la ironía se dirige a aspectos secundarios, no trascendentes. No encontramos en ella nada semejante a la ironía de un Swift o un Larra, tampoco a la de Echeverría. No se utiliza como vehículo de crítica social o política. Entretiene, quita solemridad, acerca, es también entre nos, se vuelve a ellos mismos. 
Podemos concluir que Mansilla, a través de los elementos que señalamos -sus personajes, temas, dedicatorias, del público al que se dirige, su concepción de la literatura y el escritor establece en sus causeries un círculo cerrado, un círculo que tiene un movimiento interno, de relación continua entre sus miembros, por un lado, y de vuelta al pasado, por otro. Con ese ubicarse "adentro", su contar desde adentro, y también a los que están dentro de él, y conocen sus claves, desconoce la inmigración, ese momento histórico que se vive y que él, teóricamente apoyaría a través de su apoyo a Roca. La misma inmigración que Cambaceres rechasa, pero que toma como materia literaria.

Para él, liberal, roquista, de los que "hacen", o al menos conocen la historia desde adentro, los inmigrantes no existen, ni como personajes, ni como público. Cierra el círculo, pero ellos quedan afuera.

Nada mejor para ilustrar a Mansilla que aquella tan difundida foto en que su imagen se repite, por un juego de espejos, formando un círculo cerrado.

Las figuras, que son todas la misma, miran hacia adentro, se miran, dando la espalda al que está fuera del círculo. 


\section{BIBLIOGRAFIA}

Onega, Gladys, La inmigración en la literatura argentina.

Prieto, Adolfo, La literatura autobiográfica argentina.

Viñas, David, Literatura argentina y realidad política.

Jitrik, Noé, La Revolución del 90.

Mansilla, Lucio V., Entre nos, causeries del jueves, Ed. Hachette, Buenos Aires, 1963. (Las citas han sido hechas por esta edición). 